\title{
EVALUATION OF EARTHQUAKE RESPONSE OF LOW-RISE STRUCTURES USING DESIGN CODES AND LOCAL SPECIFICATIONS
}

\author{
G.L. Hutchinson ${ }^{\text {(i) }}$ and A.Navidi ${ }^{\text {(ii) }}$
}

SYNOPSIS:

Most earthquake engineering research projects are concerned with the analysis and design of high-rise buildings. Comparisons of actual earthquake forces with pseudo-static design forces recommended by various building codes indicate that in actual earthquakes the forces in low-rise buildings can be up to three to five times the pseudo-static design forces.

This paper is concerned with evaluating and comparing the earthquake response of low-rise buildings calculated using local response spectra and real. time-histories with various Building Code Recommendations. It is shown that Building Code Recommendations underestimate the structural response.

\section{INTRODUCTION:}

Most earthquake engineering research to date has been concerned with the seismic analyses and design aspects of high-rise buildings, particularly those located in active seismic regions of the US West Coast (Ref. 3, 5, 7).

In this paper free-vibration and earthquake response of low-rise buildings are evaluated by time-history and response spectrum analyses. The main objective is to study and examine the dynamic behaviour of the low-rise buildings in relation to seismic code recommendation of various countries.

The dynamic response of low-rise steel frame buildings subjected to different seismic ground motion and response spectra are calculated. The response is determined by elastic time-history and response spectrum analyses. The fundamental translational period of vibration for low-rise structures of various heights and plan dimens ions are computed and compared with the periods obtained from equivalent single-degreeof-freedom (SDOF) models. The dynamic response properties obtained from finite element analyses are compared with the results calculated from the quasi-static building code approach. The low-rise buildings are assumed to be located in Zone III of the Uniform Building Code earthquake risk-map (Ref. 20) and are that code.

BUILDING CONFIGURATION AND IDEALIZATION OF THE STRUCTURAL MODELS:

The model of a typical low-rise steel building is shown in Fig. 1. The low-rise

$i$ Lecturer in Civil Engineering, Department of Civil Engineering, King's College, University of London, London, England.

ii Research Student, Department of Civil Engineering, King's College, University of London, England. designed to fulfill the requirement of

buildings considered are defined as single storey steel frame buildings, consisting of universal steel columns and beams with concrete slab roofs. The column and beam sizes are designed to the requirements of British Standard and the Uniform Building Codes, (Ref. 18, 20). Because of the infinite variation in configuration that can occur the models are designed to be regular in shape and completely symmetrical with varying height and plan dimensions. The structural columns are assumed to provide the lateral earthquake load resistance.

In-fill walls and partitions have been assumed to have a negligible contribution to the lateral earthquake load resistance of the structure (Ref. 12). The structural models are defined as moment resisting frames with rigid roof diaphragms. The building dimensions and calculated member sizes for all structural models considered are given in Table 1. The buildings were proportioned for a $10 \%$ base shear coefficient using the 1979 Uniform Building Code (Ref. 20).

The structural models have a three letter identification, referring to the height and the plan dimension of the structure, eg. $7 \mathrm{H} 3$ indicates the plan dimension of $7 \mathrm{~m}$ by $7 \mathrm{~m}$ and the height of 3 meters. Figure 1 shows the $7 \mathrm{~m}$ by $7 \mathrm{~m}$ dimension building configuration with height ranging from 3 meters to 6 meters.

The aspect ratio, defined as the ratio of height to the breadth, ranges from 0.33 to 1.2 over the entire range of buildings considered.

The low-rise buildings were modelled using three-dimensional finite elements. The steel frames were modelled using beam elements for the universal columns and beams with six degrees of freedom at each node, Fig. 2. The concrete slabs were assumed to be rigid plates, and each complete model consisted of 53 nodal points and 31 beam elements with 10 rigid plates. The masses of the actual building were accurately reflected in the finite element models.

BULLETIN OF THE NEW ZEALAND NATIONAL SOCIETY FOR EARTHQUAKE ENGINEERING, VOL. 16, NO. 4, DECEMBER 1983 

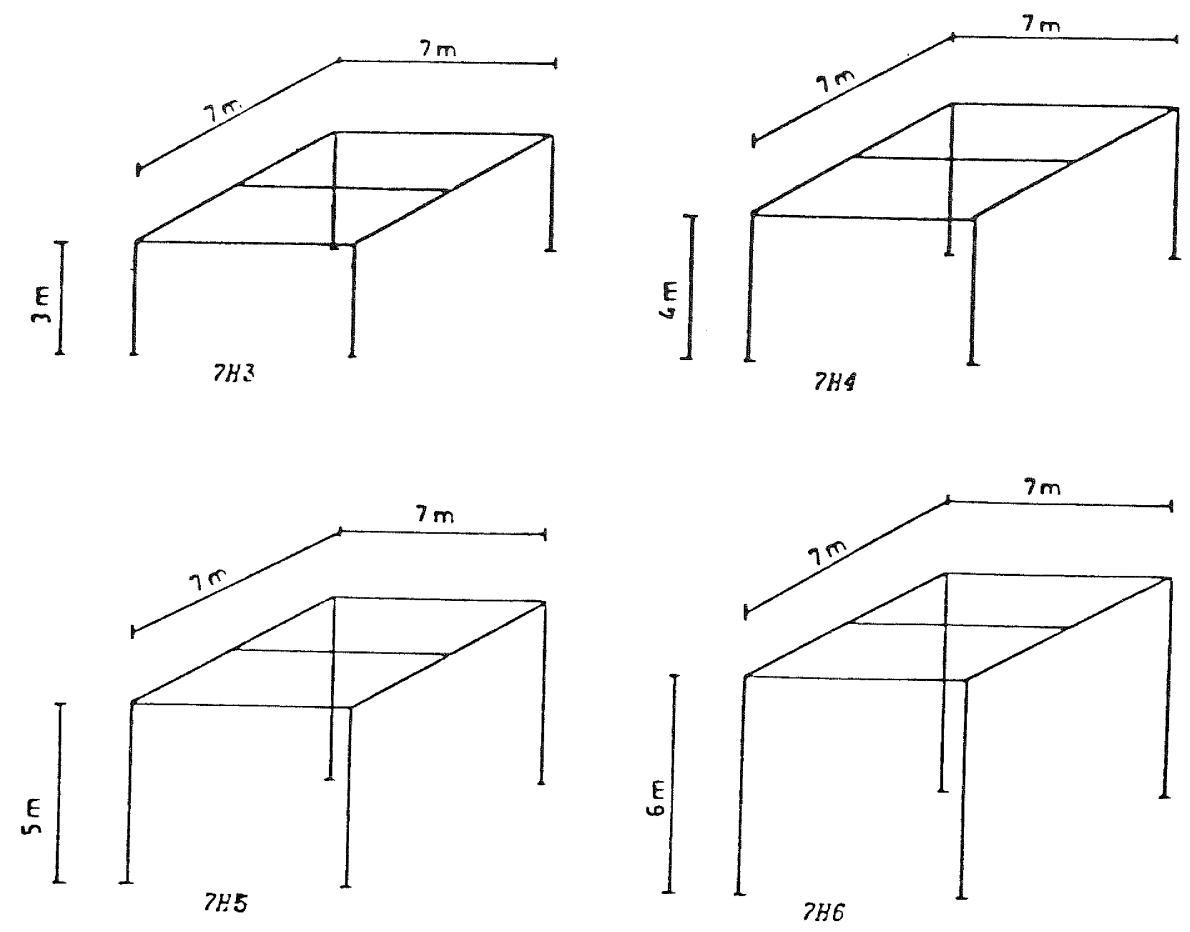

Fig. 1. Low-Rise Building Configurations.

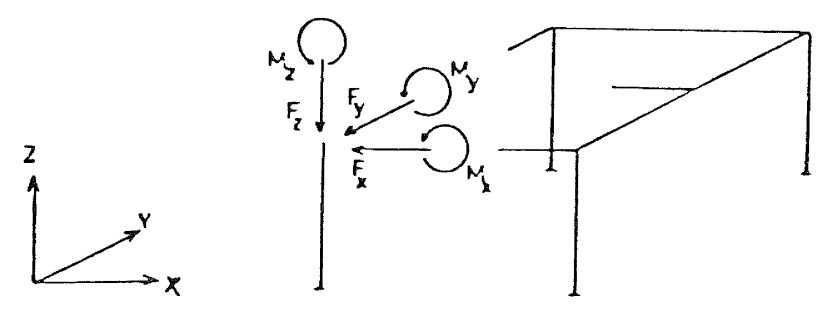

Fig. 2. Structural Idealization.
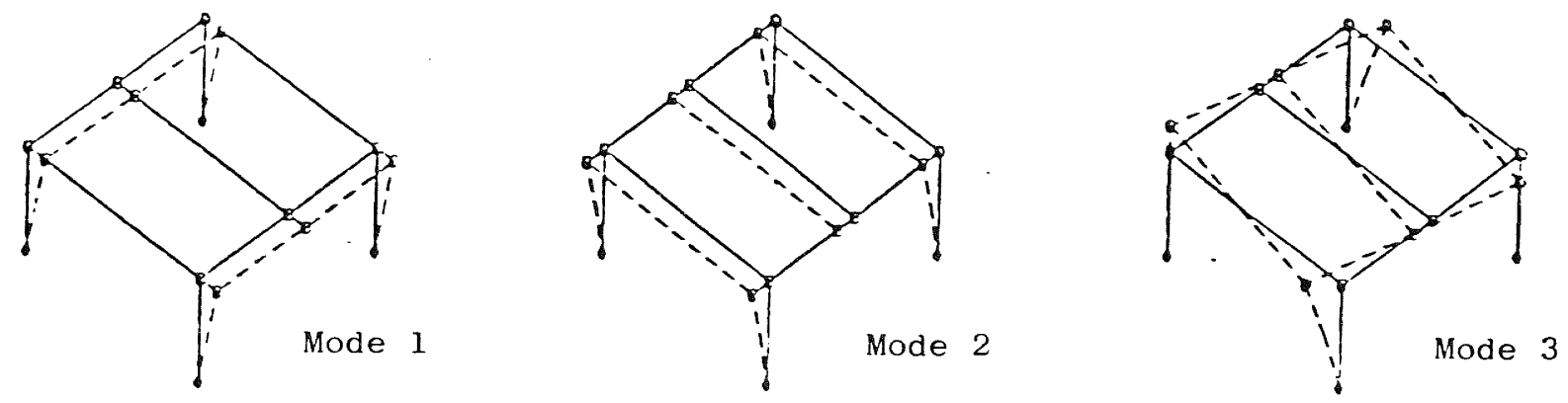

Fig. 3. Three-Dimensional View of a Structure in First Three Modes. 
FREE-VIBRATION OF STRUCTURAL MODELS:

Six natural periods of vibration and the corresponding mode shapes for the entire structural models were obtained. A modified version of the Structural Anaiysis Program (SAP IV) (Ref. 1), was used for the free-vibration analysis. The eigenvalues were found by subspace iteration with the convergence tolerance set as:

$$
\left|\frac{w_{i}^{2}-w_{i-1}^{2}}{w_{i}^{2}}\right| \leqq 0.00001
$$

in which $w_{i}$ is the natural frequency obtained at the $i^{\text {th }}$ iteration. A three-dimensional illustration of the first three mode shapes of the $6 \mathrm{H} 4$ structural model is shown in Fig. 3. The first two modes contain a predominantly side-sway motion.

Comparison of the ratio of fundamental translational periods in each orthogonal direction (mode 1 and mode 2 in all cases), provides an insight into the frequency separation of the structural models (Ref. 8). The average of this ratio for all models was found to be 0.65 .

In Fig. 4 the relationship between the structure aspect ratios and the fundamental translational period of vibration for all structures is shown. The period of vibration is increased as the aspect ratio is increased. It may be seen that, for a particular height, the fundamental period of vibration is similar for all structural models of the same height.

In Fig. 5 the relationship between the aspect ratios and the normalized structural stiffness which is obtained on the basis of the roof deflection due to a unit horizontal static force applied at the top of the structure is shown. Direct comparison ofstiffness, periods and aspect ratios indicates that an increase in the aspect ratio and the subsequent decrease in the structural stiffness, increase the fundamental period of vibration.

The fundamental translational period of vibration $T$, in most seismic codes is intended to be an estimate of the fundamental natural period of the buildings. SEAOC (Ref. 17) suggests two empirical equations based on the number of storeys and the overall geometrical configuration of the structures.

$$
\begin{aligned}
& \mathrm{T}=0.1 \mathrm{~N} \\
& \mathrm{~T}=0.091 \mathrm{H}_{\mathrm{n}} / \sqrt{\mathrm{D}}
\end{aligned}
$$

Where $\mathrm{N}$ is the number of storeys, $\mathrm{H}_{n}$ is the height of the building aboven the ground level and $D$ is the plan dimension, (all units in metres). The empirical equation suggested by the Applied Technology Council (ATC, Ref. 19), for steel building is:

$$
=0.0853 \mathrm{~h}^{\frac{3}{4}}
$$

where $h_{n}$ is the height in metres above the base to the highest level of the building.

Using Rayleigh's Method (Ref. 4) the period of vibration of single-degreeof-freedom models with masses and stiffnesses equivalent to the corresponding structural models were calculated. These and the periods obtained using equations (1) to (3) are shown in Fig. 6. From the results obtained (Fig. 4) it can be seen that the finite element analyses indicate that the periods can be assumed to be independent of the plan dimension as recommended by ATC (equation 3 ).

\section{LINEAR ELASTIC DYNAMIC ANALYSES:}

The earthquake response analysis was carried out using both time-history and response spectrum analyses for several earthquake motions. For both analyses, simultaneous multi-directional earthquake input motion was used (Ref. $2,11,14,15)$. A comparison of the dynamic results obtained from multidirectional and uni-directional analyses indicated an overall increase in axial forces of about $40 \%$ to $50 \%$. The presence of the associated bending moments led to the development of higher stresses in the column members because of the multi-directional input motions, Fig. 10.

For the purposes of this study four earthquake ground motions and six acceleration response spectra were chosen for time-history and response spectrum analyses respectively. The ground motion records are shown in Fig. 7 . These strong motions records have been obtained during magnitude $5-7$ events with duration of strong shaking varying from 4 to 20 seconds. In terms of response, the major effect of an increase in duration of ground motion is an increase in the cumulative deformation, with maximum response value remaining uneffected. The selected ground motions are chosen with reference to the velocity response spectra and their spectral intensity.

Figure 8 shows the velocity response spectra for the four corresponding input motions, the period of vibration of the structural models range from 0.35 seconds to 1.2 seconds. NS component of $\mathrm{El}$ Centro and Horizontal A component of Thessaloniki earthquake accelerograms exhibit a peaking velocity spectra close to the period range of interest. The NS component of Rumanian earthquake exhibits an ascending velocity spectra, while the velocity spectra for NS component of Rocca earthquake exhibits a sharp peak outside the period range of interest.

Six acceleration response spectra with 5\% of critical damping are shown in Fig. 9 and listed in Table 2 were used in the response spectrum analysis. Four acceleration response spectra corresponding to the four historical earthquake 

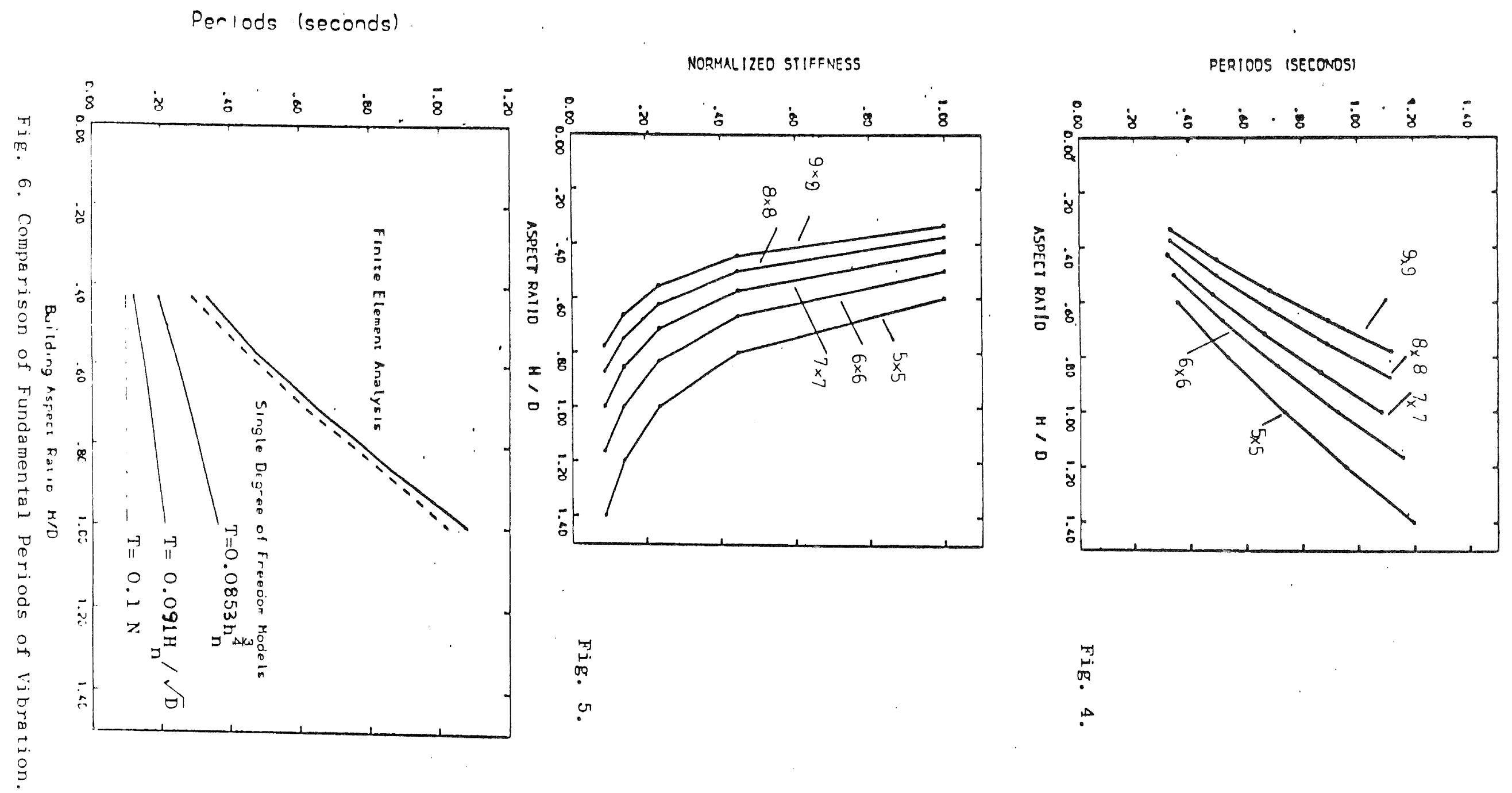
motions shown in Fig. 7, and an averaged, smooth response spectra for Rocca region of Italy (Ref. 13) are computed (Ref. 10, 16). The sixth response spectra in this analysis is the acceleration response spectra recommended by ATC (Ref. 19) for use in the building code calculations.

RESPONSE BEHAVIOUR DURING EARTHQUAKE EXCITATION:

\section{Time-History Analysis -}

In order to determine the behaviour of low-rise buildings during earthquake ground motions, the structural models chosen were:

a) structures with constant square plan dimension of $7 \mathrm{~m}$ by $7 \mathrm{~m}$ with height ranging from $3 \mathrm{~m}$ to $6 \mathrm{~m}$ (models $7 \mathrm{H} 3,7 \mathrm{H} 4,7 \mathrm{H} 5$ and $7 \mathrm{H} 6)$;

b) structures with constant height of $3 \mathrm{~m}$ with square plan dimensions ranging from $5 \mathrm{~m}$ by $5 \mathrm{~m}$ to $9 \mathrm{~m}$ by $9 \mathrm{~m}$ (models 5H3, 6H3, 7H3, 8H3 and 9H3).

The maximum base shear forces are computed as the square root of the sum of the square of the individual dynamic forces in each direction. This relationship is only applied when the maximum shear forces from both horizontal motions occur simultaneously. For all other cases where the maximum base shear force in one direction lags behind the other direction, the total maximum base shear is calculated as 1.0 times the maximum base shear in either direction, plus $1 / 3$ of the base shear in the other direction (Ref. 14).

To draw meaningful conclusions from the various earthquake input motions, it is necessary to have a basis for making comparisons. To this end the time-history analysis based on NS component of 1940 El Centro earthquake, was used as the primary analysis, and the results were used as the basis for the subsequent comparison with other earthquake motions. For this purpose the earthquake records with different properties were normalized and their magnitudes adjusted to the same magnitude as the NS El Centro earthquake. This procedure is only applied for the purpose of comparison.

The elastic base shear coefficients defined as the base shear, $V$, divided by the building weight, $W$, are tabulated for the normalized earthquake motions. The elastic base shear coefficients are interpreted as the maximum base shear that would exist when the building is under earthquake excitation. The elastic base shear coefficients in Table 3 are large, due to the fact that the ductility of the structure has so far been ignored in the elastic analyses. Although the earthquake motions are normalized, each set exhibits different base shear coefficients, indicating the uniqueness of the characteristics of each individual input motion. the base shear forces is evident for Thessaloniki and Rocca earthquakes, but for the Rumanian and El Centro earthquakes the base shear coefficients exhibit random behaviour. Table 3 also shows that for models of equal height but varying plan dimensions, the base shear coefficients is almost constant. In Fig. 12 the dynamic response due to the NS EI Centro earthquake input motion is shown. The variation of these dynamic forces follow the behaviour pattern of the input motion. In Fig. 10 and 11 the computed stress history for all four input motions is shown, demonstrating the fact that the peak stress occurs at the times corresponding to the peak ground motion. Due to the increase in overturning moment of the structure with increasing height, the axial forces for all input ground motions are increased. The maximum base shear coefficients obtained from timehistory analyses will be used for comparison with the results obtained from quasi-static building code approach and the design response spectrum analyses.

\section{Response Spectrum Analysis -}

The ATC response spectra was applied to all structural models and the computed response spectra were applied to the models 7H3, 7H4, 7H5 and 7H6.

The dynamic forces obtained by applying the ATC design response spectra to all structural models are shown in Fig. 13. Due to the overall overturning moments on the buildings, the axial forces increase as the aspect ratio increases and the lateral shear forces in both directions reduce with the increasing aspect ratios, Fig. 13. This behaviour is consistent with the dynamic characteristics of the structures.

Comparisons between various computed response spectra are shown in Fig. 14. It can be seen that the general trend for Rocca is a decrease in dynamic forces as the aspect ratio is increased. on the other hand, the dynamic forces for Rumania show the reverse relationship. This is because of the shape of the Rumanian response spectra; where the fundamental periods of vibration of the models are associated with higher spectral accelerations than the corresponding periods for the Rocca spectra. The general shape of the NS EI Centro and Thessaloniki spectra exhibit alike patterns, because the relationship between dynamic forces and the aspect ratios are quite similar.

Discrepancies between the results obtained using different recorded response spectra are shown in Fig. 14, these depend in part on the general shape of the input acceleration response spectra.

The computed response of the linearly elastic systems using the time-history analysis shows good agreement with the results obtained from response spectrum analysis. The average ratio of these results is between 0.97 to 1.4 . For both analyses the displacement at the top of the structural model is increased as the aspect ratio is increased and 

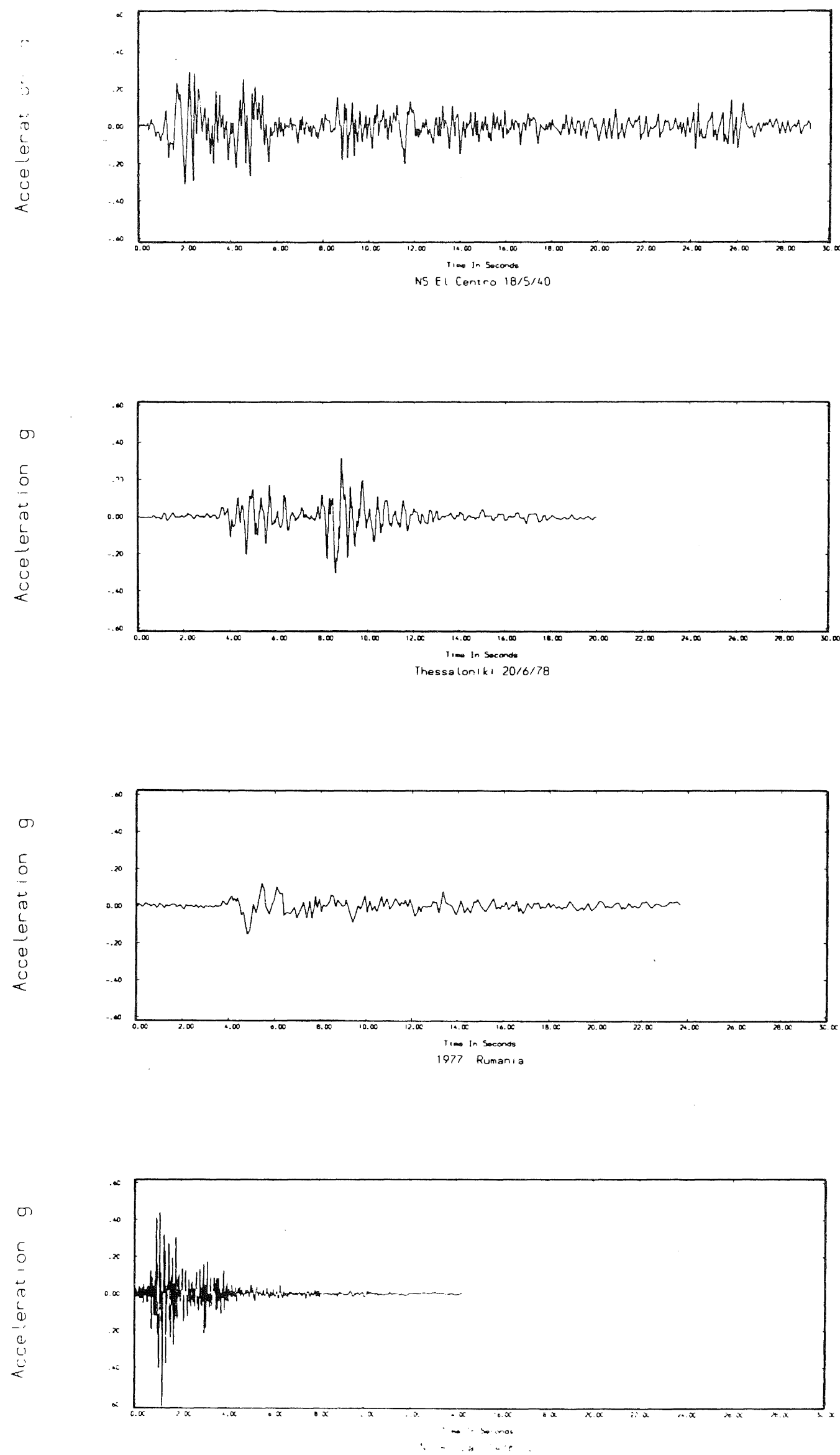

Fig. 7.- Strong Earthquake Motions. 


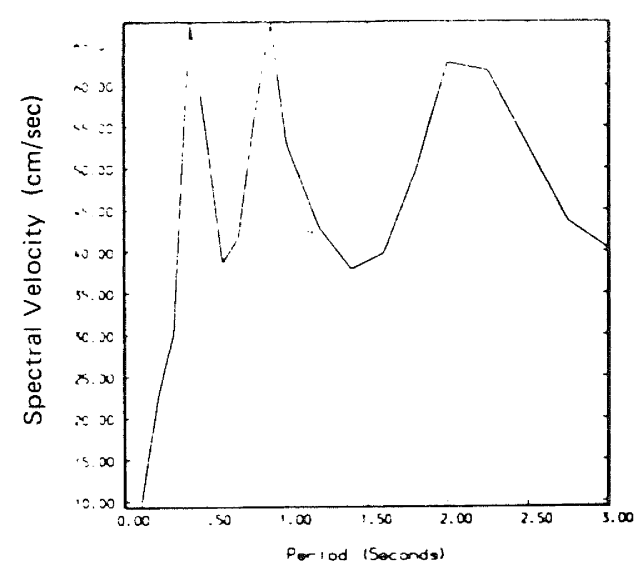

NS El Centro

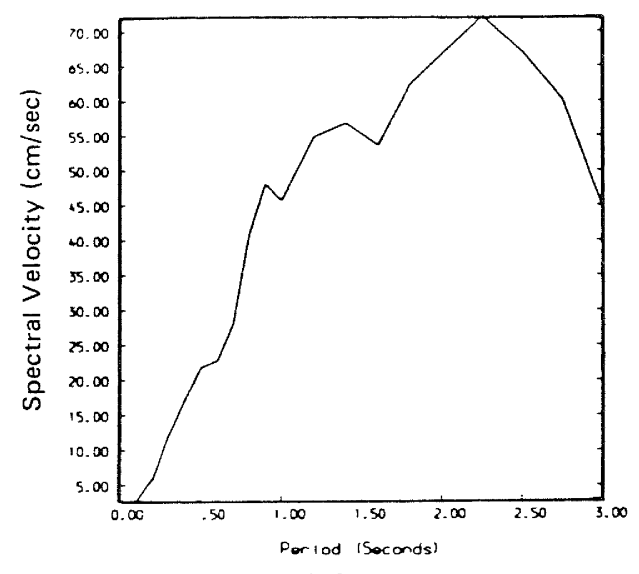

NS Rumania

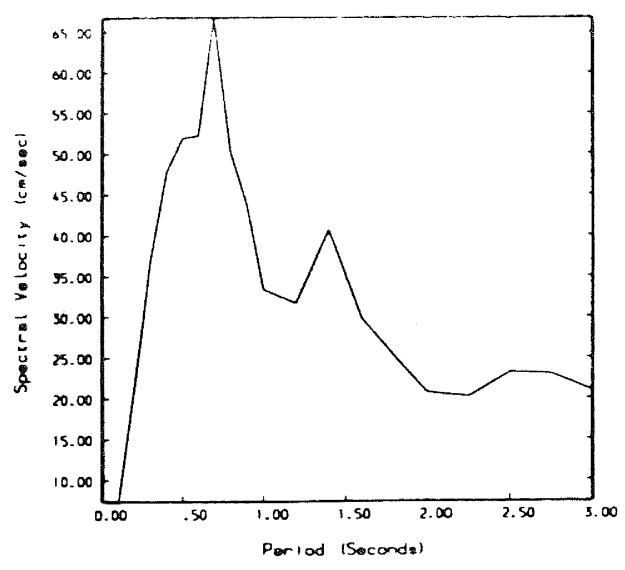

Thessaloniki Horiz. A

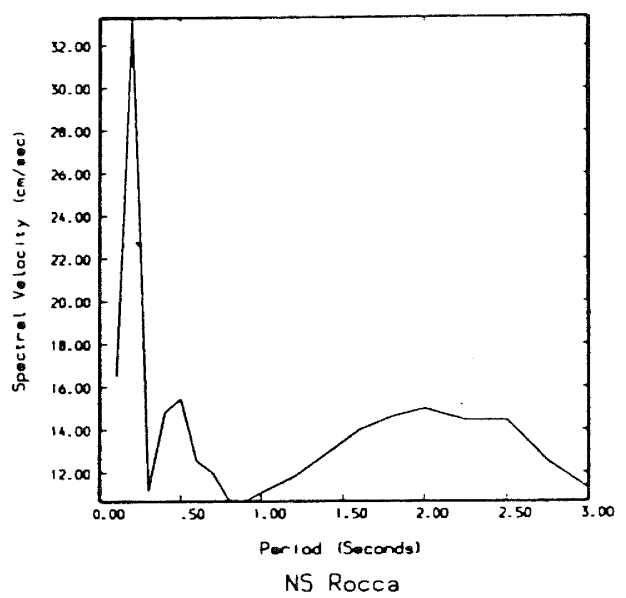

Fig. 8. Velocity Response Spectra.
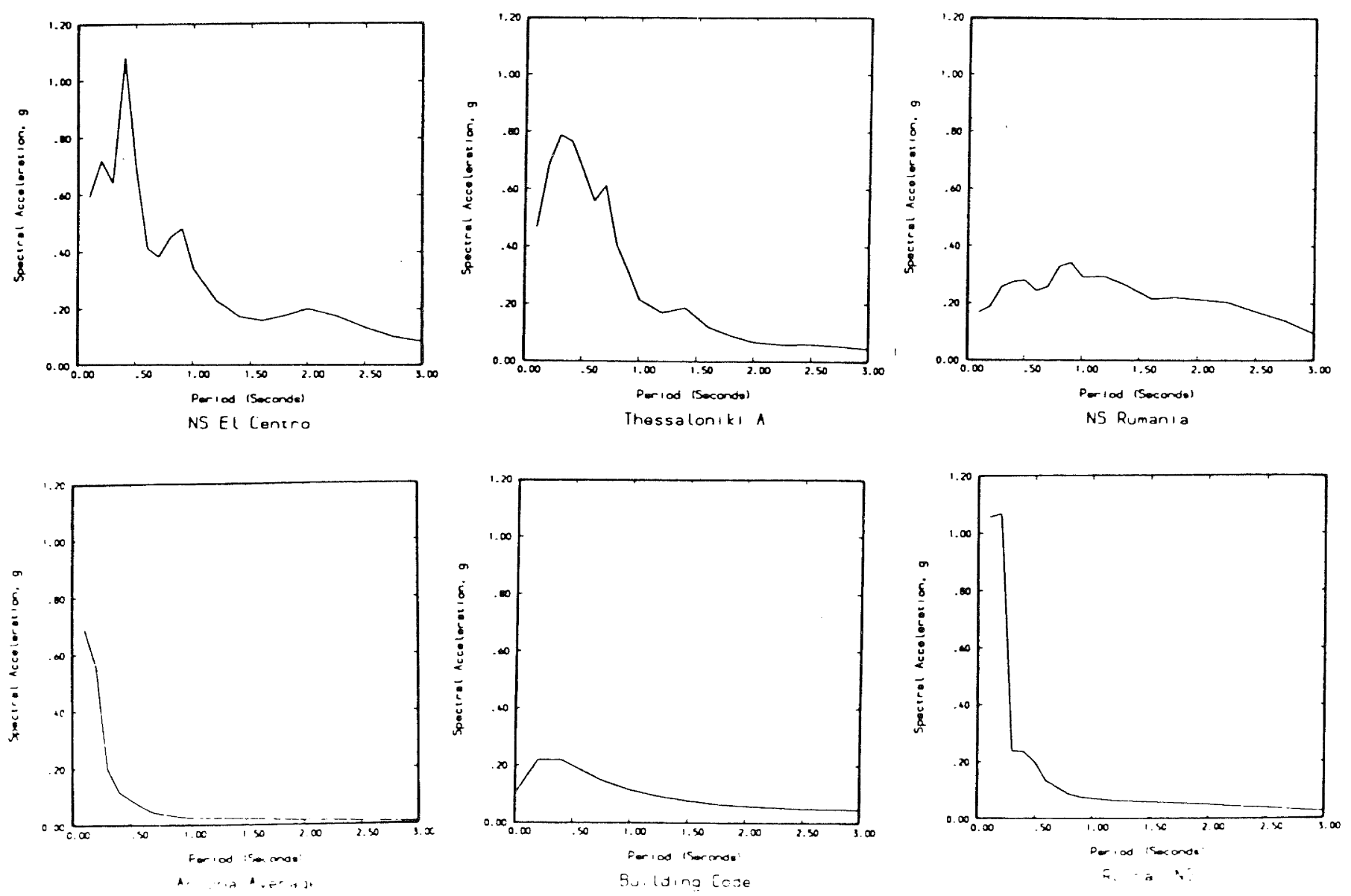

Fig. 9. Acceleration Response Spectra. 

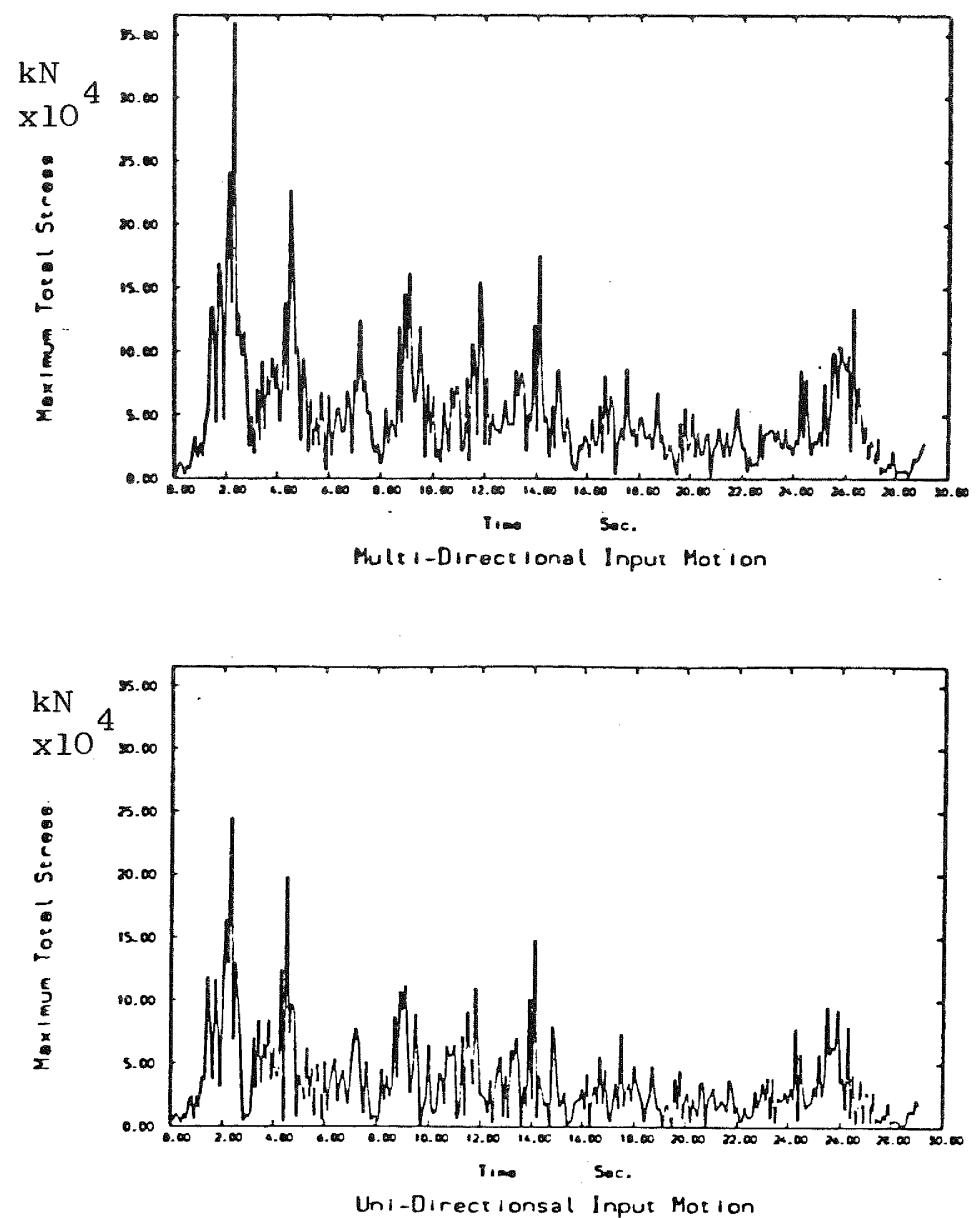

Fig. 10. NS El Centro Earthquake Response.
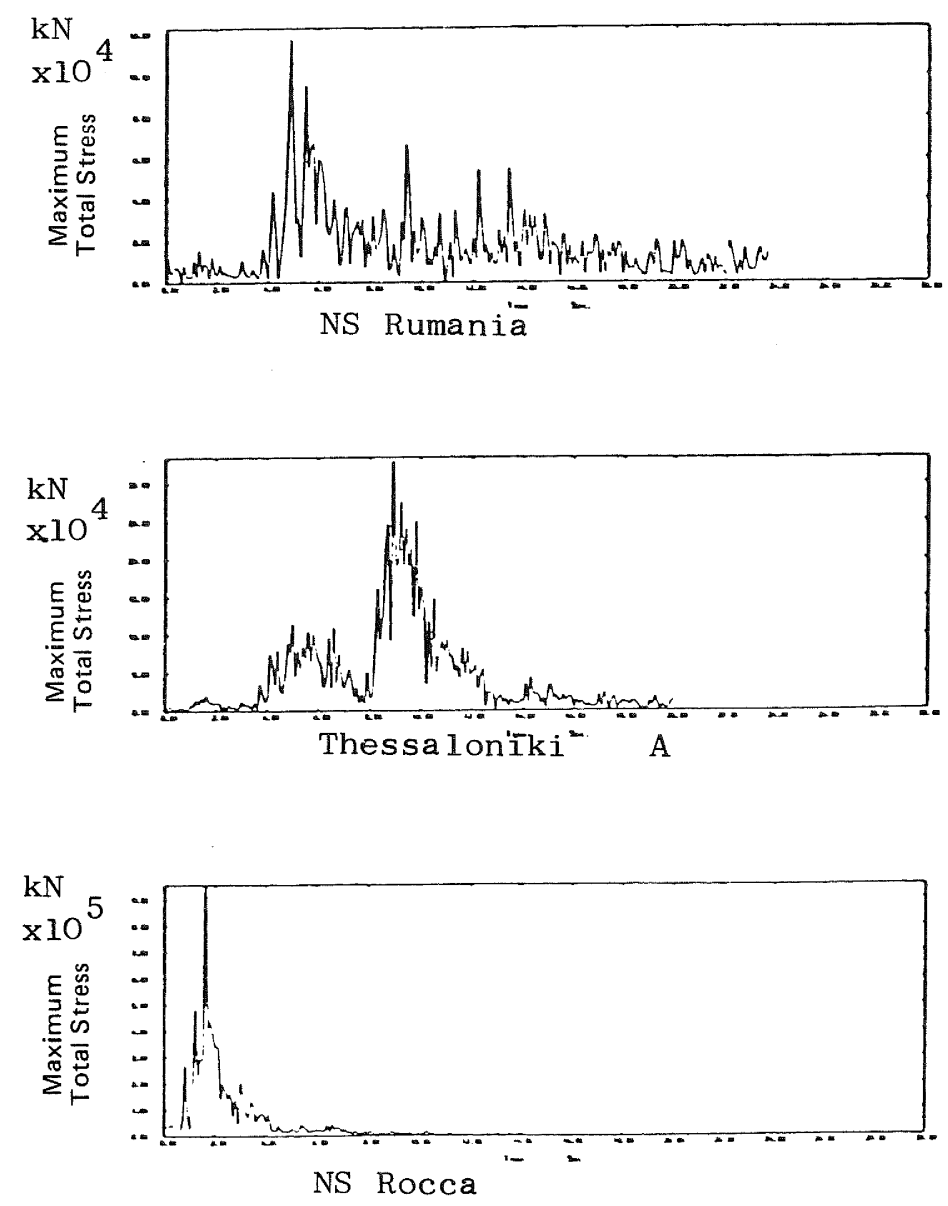

Fig. 11. Time- History Response. 
is identical for structural models of similar height. Figure 15 shows the elastic base shear coefficients versus natural periods of vibration for results obtained using the response spectrum analysis. These computed values do not of course take into account the general ductility and the energy absorption capacity of the structures; hence the high values of the coefficients when compared with values employed in the design of the structures originally ( $10 \%$ in the design analysis).

\section{EARTHQUAKE RESISTANCE BUILDING CODES} APPROACH:

In using the building code approach, the design base shear estimated from the product of the building weight and a seismic coefficient. In many cases it appears that the value of seismic coefficient determined by the code is too low for the structures concerned (Ref. 6). The earthquake loadings prescribed in most current seismic codes in the world (Ref. 6) may be represented as follows:

$$
V=C(Z, I, S, K, T) W
$$

where

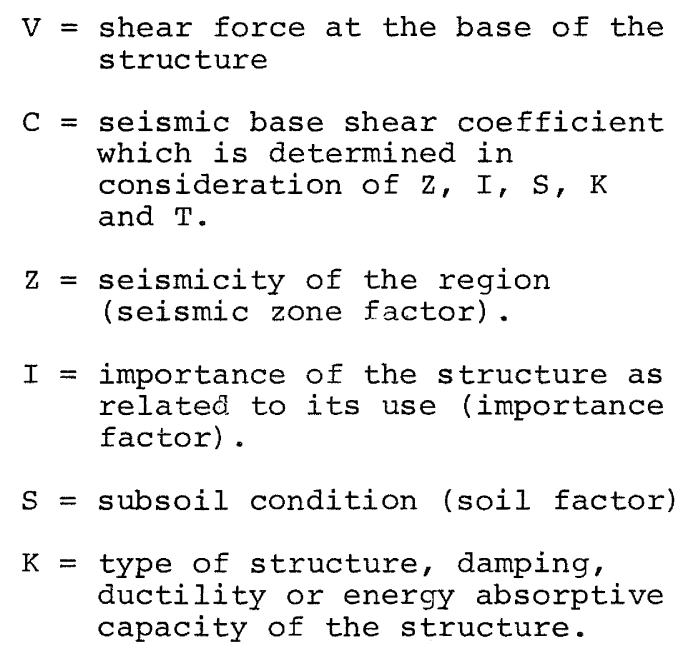

$\mathrm{T}=$ natural period of vibration of the structure in the direction under consideration.

$W=$ total vertical load used for seismic calculations.

Two important factors mentioned above are $\mathrm{K}$ which takes into account the ductility and $T$, the translational natural period of vibration which takes into consideration the stiffness of the structure. It was shown in Fig. 6 that the empirical values obtained for periods of vibration are much less than values obtained from the free-vibration analysis. This is because the empirical equations recommended by various codes have been formulated for real steel frame buildings. The Uniform Building Code (Ref. 20) estimation of $\mathrm{T}=0.1 \mathrm{~N}$ for single storey buildings with higher than normal columns' length significantly underestimates the value of $\mathrm{T}$ as shown in Fig. 6.
The results obtained by applying the constant value of ductility to both dynamic analyses (Ref. 9) are compared in Table 4 with the results obtained from the building code approach. The code approach takes into account the general ductility and energy absorption capability of the structures. The entries in Table 4 represent the maximum time-history and response spectrum base shears normalised to the corresponding base shears calculated using Uniform Building Code approach. This comparison shows that for the frames that are higher than average single storey i.e. low-rise buildings, there is a good agreement between the dynamic analyses and design code approach.

The entries in Table 5 represent the maximum base shears computed by using the ATC recommended design response spectra normalized to the base shears calculated from building code approach. These ratios indicate that the ATC values are almost twice the values of building code approach and that the ratio decreases as the height of the structures are increased. It can therefore be seen that the code underestimates the maximum base shears developed in low-rise buildings and that as the height of the structure is increased the empirical formulation recommended by seismic design codes, yields a better estimation of the base shear forces in the column members.

A comparison of the lateral base shear coefficients of the Uniform Building Code of the United States (1979), the Japanese Seismic Code, the New Zealand Seismic Code, the Turkish Building Code, the Iranian Building Code, and the idealized spectrum curves of 1940 NS EI Centro, 1978 Thessaloniki, 1977 Rumania and 1972 Rocca earthquakes are shown in Fig. 16 and 17 . The idealized spectrum curves are the results obtained with the ductility of the structures taken into consideration.

As can be seen from the comparative curves of Fig. 17, the shaded area indicates that the forces involved in short period structures are considerably higher per unit mass than those for high-rise buildings.

\section{SUMMARY AND CONCLUSIONS:}

The free-vibration analysis provides valuable information about the earthquake response characteristics of buildings.

The periods of vibration for various low-rise buildings of equal heights are similar, thereby implying that they are independent of plan dimensions and dependent on the height. This is in agreement with empirical equation recommended by ATC in which the period is a function of height only (Ref. 19). The periods calculated for single-degreeof-freedom models are in good agreement with the results obtained from the freevibration analysis.

The elastic base shear coefficients are considerably higher than the code base shear coefficients. The base shear 

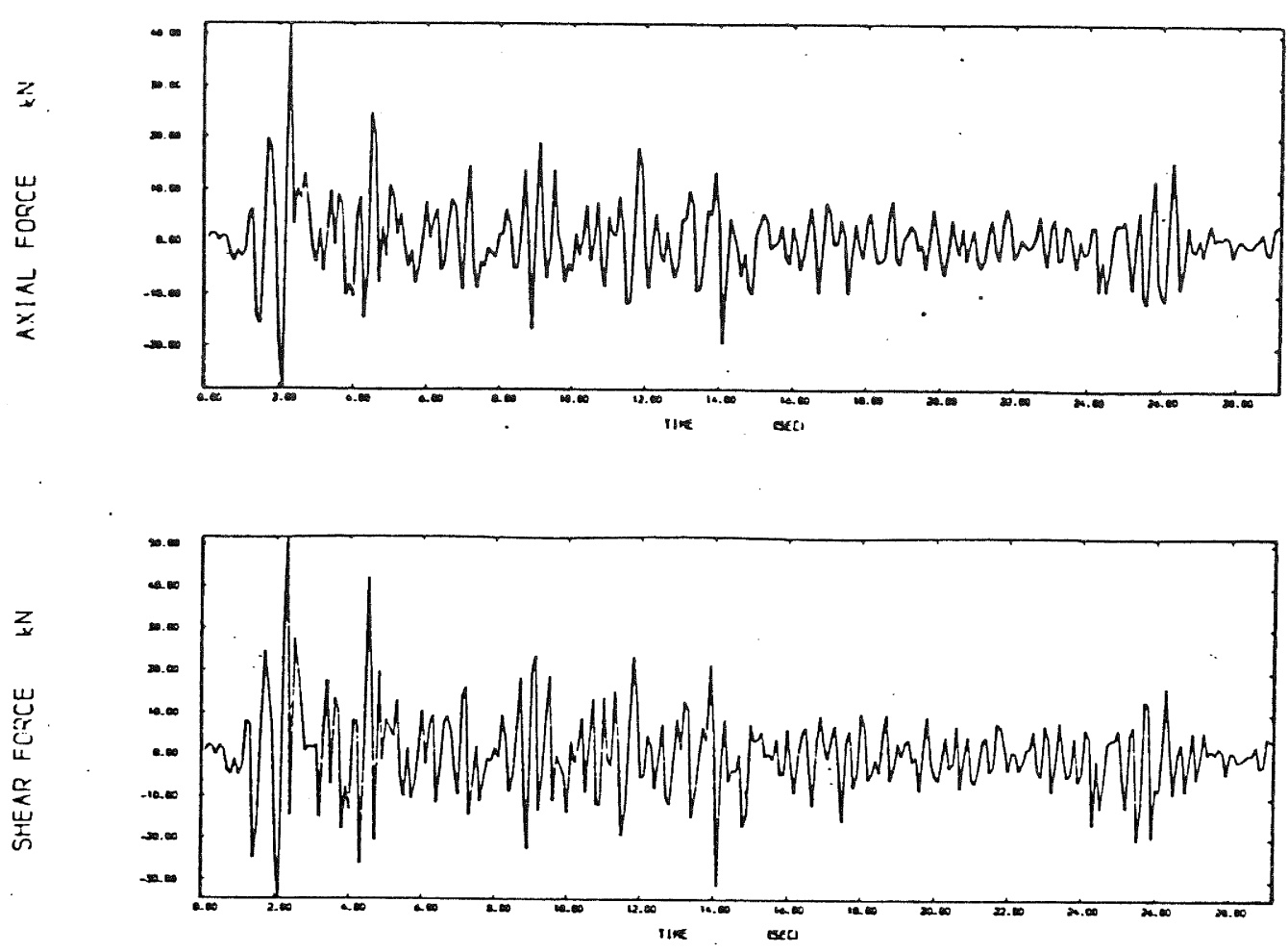

Fig. 12. NS El Centro Dynamic Response History.
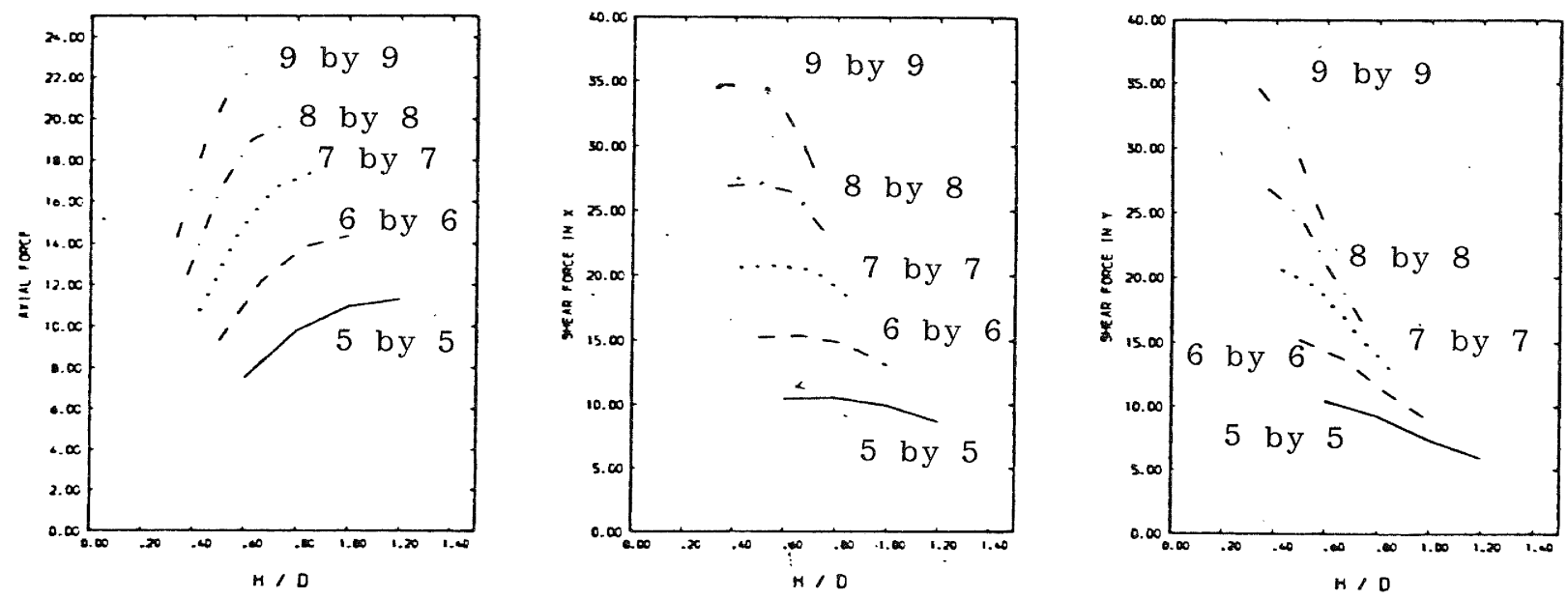

Fig. 13. Response Spectrum Analysis (ATC Design Spectra). 

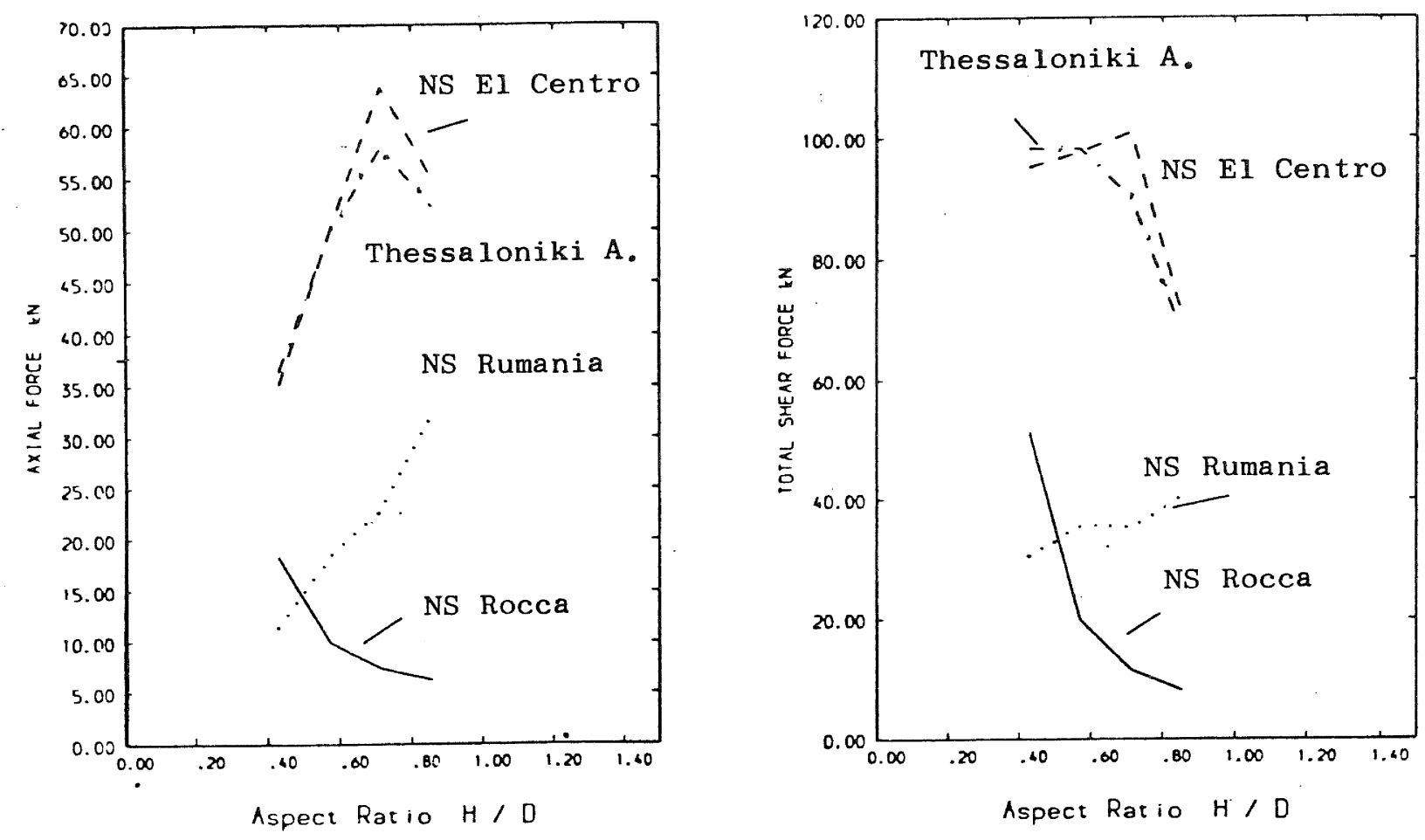

Fig. 14.- Response Spectrum Analysis (historical Response Spectra).

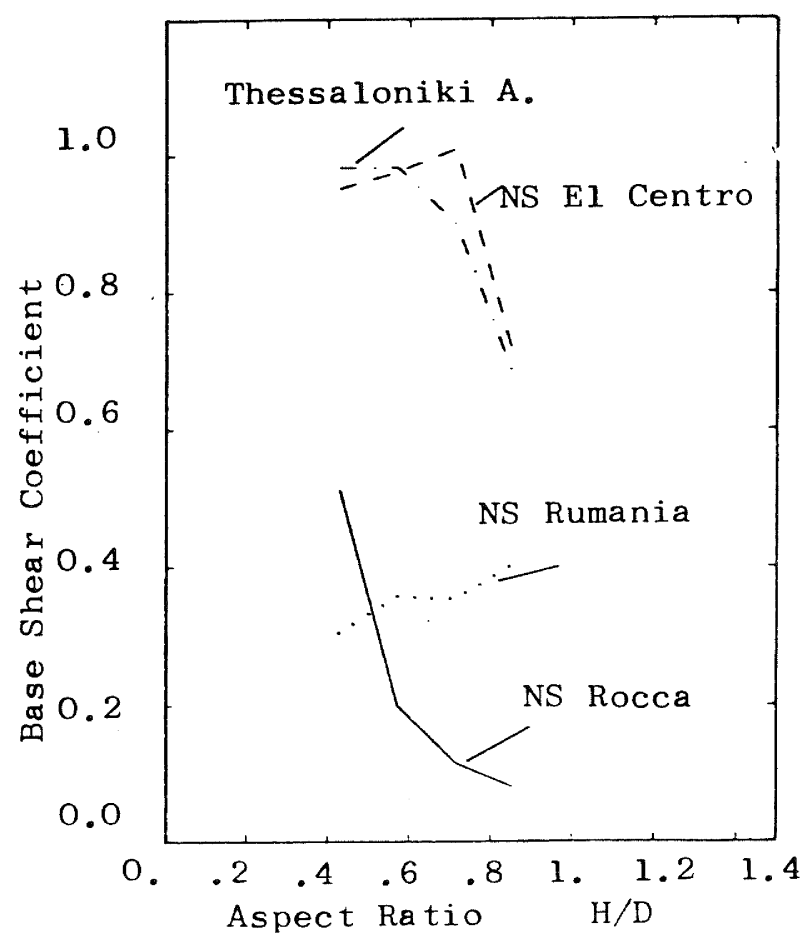

Fig. 15.- Elastic Base Shear Coefficients. 
coefficients obtained by taking into account the general ductility of the structures are higher than the building code coefficients. The concurrent action of multi-directional earthquake response can considerably increase the total shear force in column members. In current seismic codes (Ref. 6), the phenomenon of simultaneous earthquake response along the two axes of a horizontal plane is not considered.

The base shear coefficients of highrise buildings (i.e. buildings with higher aspect ratios) are in better agreement with the code base shear coefficients than buildings with lower aspect ratios. The majority of the structures fall into low-rise category and care should therefore be taken when applying the building code recommendations to low-rise buildings.

\section{REFERENCES :}

1. Bathe, K.J., Wilson, E.L., and Peterson, F.E., "SAP IV - A Structural Analysis program for static and Dynamic Response of Linear System" Report No EERC 73-11, Earthquake Engineering Research Centre, University of California at Berkeley, Berkeley, Calif. June 1973.

2. Blume, J.A., "Building Columns under Strong Earthquake Exposure." Journal of the Structural Division, ASCE, Vol. 97, No. ST 9, Sept. 71.

3. Blume, J.A., "Hi-Rise Building Characteristics and Response Determined from Nuclear Seismology." Bulletin of Seismological Society of America, Vol. 62, No. 2, Apr. 72, pp. 519-540.

4. Clough, R.W., and Penzien, J., "Dynamics of Structures", McGraw Hill, New York, 1975.

5. Davidson, J.H., and Adams, P.F., "Stability of Braced and Unbraced Frames", Journal of the Structural Division, ASCE, Vol. 100. No. ST 2, Feb. 74

6. Earthquake Resistant Regulations A World List, International Association for Earthquake Engineering, August 1980.

7. Harris, J.R., Fenves, S.J., Wright, R.N., "Logical Analysis of Tentative Seismic Provisions," Journal of the Structural Division, ASCE, Vol. 107, No. ST 8, August 1981.

8. Hart, G.C., DiJulio Jr., R.M., and Lew, M., "Torsional Response of High-Rise Buildings", Journal of the Structural Division, ASCE, Vol. 101, No. ST 2, Feb. 1975.

9. Humar, J.L., "Seismic Design of Buildings Using a Time-History Method," Proceedings, Third Canadian Conference on Earthquake Engineering, June 1979, pp. 609-651.
10. Hudson, D.E., and Brady, A.G., "Strong motion earthquake accelerograms", Report No. EERL 71-50, Earthquake Engineering Research Laboratory, California Institute of Technology, Pasadena, California 1971 .

11. Hutchinson, G.L., and Tscinios, T.G., "Theoretical assessment of the behaviour of arch dams for seismic loading," I.C.E., London 1980.

12. Montgomey, C.J., and Hall, W.J. "Seismic Design of Low-Rise Steel Buildings", Journal of the Engineering Mechanics Division, ASCE, Vol. 105, No. ST 10, Oct. 1979.

13. Navidi, A., "Response Spectra for Ancona-Rocca, Italy," Report No. 81-1, Department of Civil Engineering, King's College, London.

14. Newmark, N.M., "Earthquake Resistant Design and ATC Provision," Proceedings, Third Canadian Conference on Earthquake Engineering, June 1979, pp. 745-775.

15. Newmark, N.M., and Rosenbluth, E., "Fundamentals of Earthquake Engineering," Prentice Hall Inc. 1971 .

16. Nigam, N.C., and Jennings, P.C., "Digital Calculation of Response Spectra from Strong-motion earthquake Records", Earthquake Engineering Research Laboratory, California Institute Technology, Pasadena, California 1968.

17. Recommended Lateral Force Requirements, Structural Engineers Association of California (SEAOC), California, 1978 .

18. Steel Designers' Manual, Fourth Edition, Crosby Lockwood \& Sons Ltd, 1975.

19. "Tentative Provisions for the Development of Seismic Regulations for Buildings", Applied Technology Council, Report ATC 3-06, June 1978.

20. Uniform Building Code, International Conference of Building Officials, Whittier, California, 1979. 


\section{TABLE 1}

$\mathrm{E}=$ Modulus of Elasticity $=210 \mathrm{kN} / \mathrm{mm}^{2}$

$\mathrm{W}=$ load due to weight of concrete roof and live load; in $\mathrm{kN}$

The universal beams and columns as listed in BS4: Part 1: 1972

\begin{tabular}{|l|c|cc|cc|}
\hline Models & $\begin{array}{c}\text { Load } \mathrm{k} \\
\mathrm{kN}\end{array}$ & $\begin{array}{c}\text { Universal Columns } \\
\text { Serial Size kg/m } \\
\mathrm{mm}\end{array}$ & \multicolumn{2}{|c|}{$\begin{array}{c}\text { Universal Beams } \\
\text { Serial Size } \mathrm{kg} / \mathrm{m} \\
\mathrm{mm}\end{array}$} \\
\hline $5 \mathrm{H} 3,5 \mathrm{H} 4,5 \mathrm{H} 5,5 \mathrm{H} 6$ & 200 & $203 \times 203$ & 60 & $305 \times 102$ & 33 \\
$6 \mathrm{H} 3,6 \mathrm{H} 4,6 \mathrm{H} 5,6 \mathrm{H} 6$ & 300 & $203 \times 203$ & 86 & $356 \times 171$ & 51 \\
$7 \mathrm{H} 3,7 \mathrm{H} 4,7 \mathrm{H} 5,7 \mathrm{H} 6$ & 400 & $254 \times 254$ & 89 & $457 \times 152$ & 60 \\
$8 \mathrm{H} 3,8 \mathrm{H} 4,8 \mathrm{H} 5,8 \mathrm{H} 6$ & 500 & $254 \times 254$ & 107 & $457 \times 191$ & 89 \\
$9 \mathrm{H} 3,9 \mathrm{H} 4,9 \mathrm{H} 5,9 \mathrm{H} 6$ & 630 & $254 \times 254$ & 3.32 & $533 \times 210$ & 113 \\
\hline
\end{tabular}

TABLE 2

Properties of Response Spectra for 5\% of Critical Damping

\begin{tabular}{|l|c|c|}
\hline Response Spectra & $\begin{array}{c}\text { Max. Spectral } \\
\text { Acceleration }\end{array}$ & $\begin{array}{l}\text { Spectrum Intensity (cm) } \\
\text { SI } 0.05\end{array}$ \\
\hline NS El Centro & $1.08 \mathrm{~g}$ & 116.5 \\
NS Rumania & $0.342 \mathrm{~g}$ & 115.0 \\
A Thessaloniki & $0.787 \mathrm{~g}$ & 80.1 \\
NS Rocca & $1.068 \mathrm{~g}$ & 35.2 \\
Average Rocca & $0.69 \mathrm{~g}$ & 15.3 \\
ATC-03 Design & $0.22 \mathrm{~g}$ & 40.1 \\
\hline
\end{tabular}

\section{TABLE 3}

Maximum Normalized Elastic Base Shear Coefficients

\begin{tabular}{|c|c|c|c|c|}
\hline Models & NS EI Centro & NS Rumania & NS Rocca & $\begin{array}{c}\text { Thessaloniki } \\
\text { Horizontal A }\end{array}$ \\
\hline 7H3 & .81 & .53 & 1.10 & .75 \\
$7 \mathrm{H} 4$ & .86 & .50 & .88 & .69 \\
$7 \mathrm{H} 5$ & .94 & .57 & .62 & .44 \\
$7 \mathrm{H} 6$ & .89 & .70 & .46 & .41 \\
& & & & .82 \\
$6 \mathrm{H} 3$ & .85 & .53 & 1.02 & .79 \\
$8 \mathrm{H} 3$ & .82 & .52 & 1.01 & .81 \\
$9 \mathrm{H} 3$ & .85 & .55 & 1.10 & .83 \\
\hline
\end{tabular}




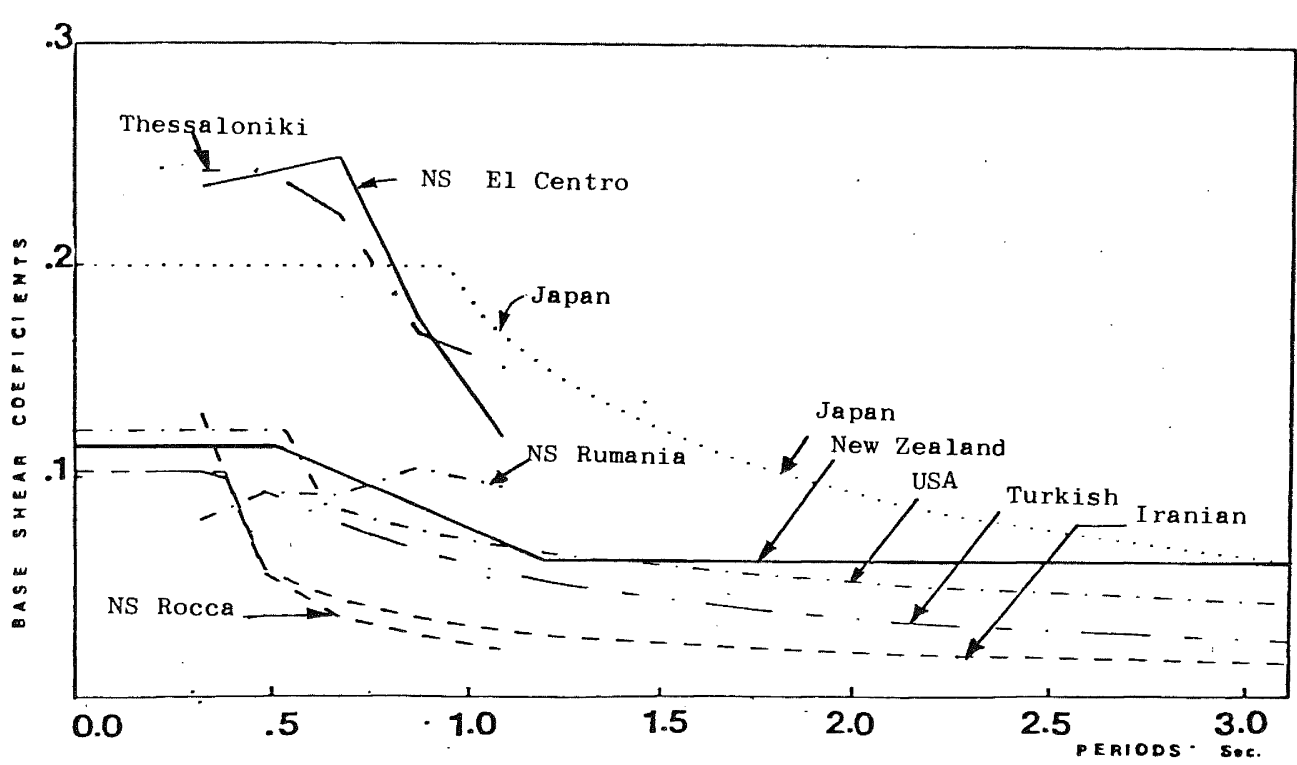

Fig. 16. Comparison of Base Shear Coefficients.

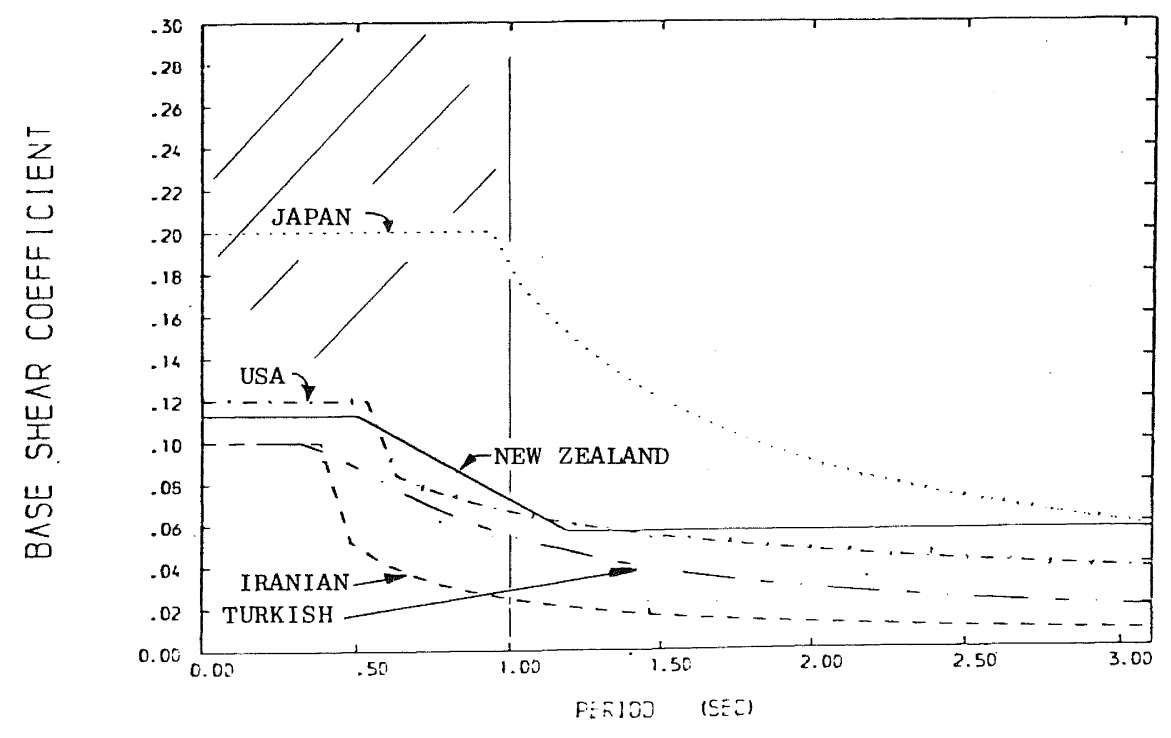

Fig. 17. Comparison of Base Shear Coefficients.

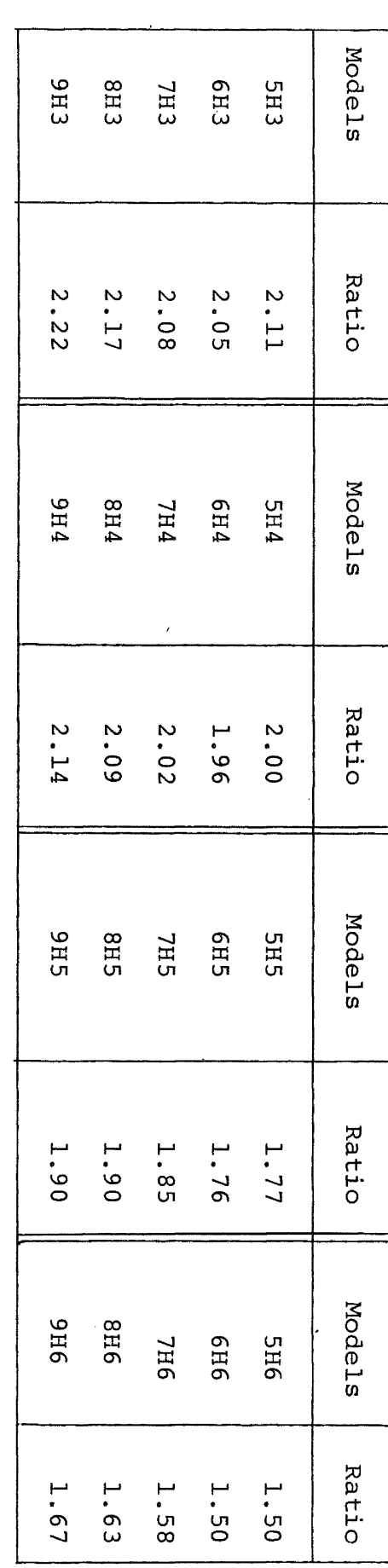

